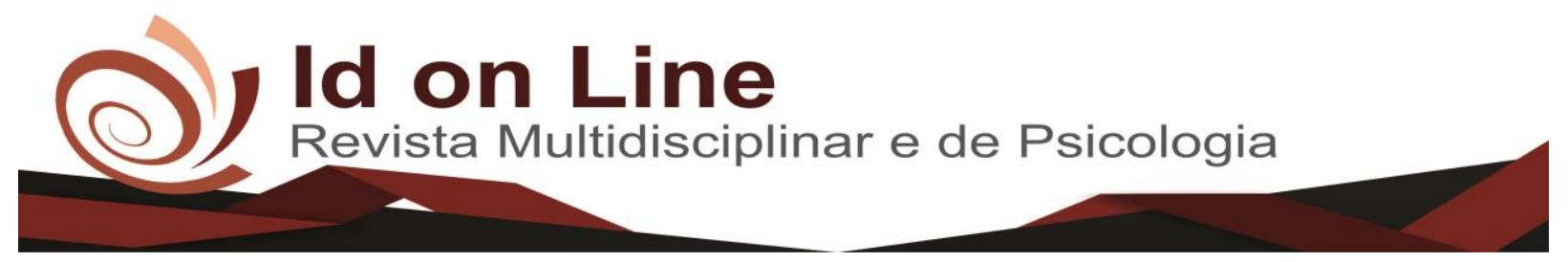

Artigo

\title{
O Direito Internacional Humanitário Frente à Problemática da Mutilação Genital Feminina
}

\author{
José Humberto de Alencar Filhol ; Miguel Melo Ifadireó²; José Antônio de Albuquerque Filho ${ }^{3}$
}

\begin{abstract}
Resumo: A presente pesquisa apresenta-se como uma tentativa de ampliação das perspectivas sobre as interações simbólicas - culturais, sociais e jurídicas - do ser humano, no rastro das mais distintas formas de sociabilidade. De modo que, o trabalho tem como objetivo a tentativa de compreender e acolher a complexidade das abordagens jusfilosóficas edificadas em cima de experiências entre meninas e mulheres vítimas da mutilação genital e as normativações em sociedade. O estudo fez uso da metodologia de pesquisa de revisão bibliográfica como instrumento de análise. Quanto à abordagem, esta se caracterizou por fazer uso de procedimentos metodológicos, predominantemente, qualitativos, oriundos da intepretação de ideias, categorias, signos e discursos, buscando assim, entender os problemas apresentados e procurando racionalizar a questão sob o foco da multiculturalidade. Os resultados permitiram a propositura de uma análise crítico-reflexiva sobre a mutilação genital feminina e seus reflexos no direito internacional humanitário. Além do mais, os resultados permitiram observar que na atualidade ainda persistem práticas culturais que carecem de reflexões e ressignificações por parte da Teoria Geral dos Direitos Humanos. Finalmente, conclui-se que a prática da mutilação genital feminina constitui uma notória violação aos direitos e garantias fundamentais da humanidade, em que os motivos sustentados para a continuidade dessa prática, demonstram um maciço e enviesado conteúdo de domínio masculino, cujo o objetivo é deter a coisificação da mulher submissa, objeto de exposição masculino.
\end{abstract}

Palavras-chave: Violência. Violações aos Direitos Humanos. Mutilação Genital Feminina. Globalização. Teoria dos Direitos Humanos.

\section{International Humanitarian Law in the Problem of Female Genital Mutilation}

\begin{abstract}
The present research is an attempt to broaden the perspectives on the symbolic interactions - cultural, social and legal - of the human being, in the wake of the most different forms of sociability. Thus, the objective of the work is to try to understand and accept the complexity of jusphilosophical approaches based on experiences between girls and women victims of genital mutilation and normative practices in society. The study made use of the literature review methodology as a tool for analysis. As for the approach, it was characterized by methodological procedures, predominantly qualitative, resulting from the interpretation of ideas, categories, signs and discourses, seeking to understand the problems presented and seeking to rationalize the issue under the focus of multiculturalism. The results allowed the presentation of a critical-reflexive analysis on female genital mutilation and its repercussions in international humanitarian law. Moreover, the results allowed us to observe that cultural practices still lacking in the present day, which require reflection and re-signification by the General Theory of Human Rights. Finally, it was concluded that the practice of female genital mutilation constitutes a
\end{abstract}

\footnotetext{
${ }^{1}$ Graduado em Direito pelo Centro Universitário Dr. Leão Sampaio. Tabelião Interino do Cartório de Araripe/ Pernambuco. Pesquisadorvoluntário do Laboratório Interdisciplinar de Estudos da Violência (LIEV)/UNILEÃO. Correio Eletrônico: jhfilho.uk@live.com;

${ }^{2}$ Doutor em Sociologia (UFPE). Professor do Mestrado Profissional em Ensino em Saúde do Centro Universitário Dr. Leão Sampaio (UNILEÃO). Professor Assistente da Universidade de Pernambuco (UPE). Doutor em Sociologia pelo Programa de Pós-Graduação em Sociologia da Universidade Federal de Pernambuco. Professor temporário do curso de Direito da Faculdade de Ciências Humanas do Sertão Central (FACHUSC).Pesquisador-líder do Laboratório Interdisciplinar em Estudos da Violência no Centro Universitário Dr. Leão Sampaio (LIEV-UNILEÃO). Advogado. Licenciado em Pedagogia pela Faculdade Kurios (FAK).

Correio Eletrônico: crioulo.miguelangelo.melo@gmail.com;

${ }^{3}$ Doutorando pelo Programa de Pós-Graduação em Letras da Universidade do Estado do Rio Grande do Norte. Mestre em Direito pela Universidade Católica de Pernambuco. Professor temporário do curso de Direito da Faculdade de Ciências Humanas do Sertão Central (FACHUSC). Pesquisador-colaborador do Laboratório Interdisciplinar em Estudos da Violência no Centro Universitário Dr. Leão Sampaio (LIEV-UNILEÃO). Correio Eletrônico: albuquerque_filho@hotmail.com.
}

14 Id on Line Rev. Mult. Psic. V.13, N. 43, p. 14-29, 2019 - ISSN 1981-1179

14 Id on Lição eletrônica em http://idonline.emnuvens.com.br/id 
gross violation of the fundamental rights and guarantees of humankind, where sustained reasons for the continuity of this practice demonstrate a massive and skewed masculine domain content whose purpose is to deter the conceit of the submissive woman, object of male exposure.

Keywords: Violence. Violations of Human Rights. Female Genital Mutilation. Globalization. Human Rights Theory.

\section{Considerações Iniciais}

A presente pesquisa apresenta-se como uma tentativa de ampliação das perspectivas sobre as interações simbólicas - culturais, sociais e jurídicas - do ser humano, no rastro das mais distintas formas de sociabilidade. De modo que, o trabalho em tela buscará compreender e acolher a complexidade das abordagens jusfilosóficas edificadas em cima de experiências entre sujeitos e as normativações sobre estes em sociedade, tendo como foco a propositura da análise crítico-reflexiva sobre a mutilação genital feminina sob o foco do direito internacional humanitário. A análise socio-antropológica de tais práticas permitirá, por um lado, que as fronteiras determinantes entre os gêneros e o direito sejam borradas; e por outro lado, desejase que esta analise contribua com o avanço das discussões jusfilosóficas, fugindo ao predomínio das interpretações advindas da dogmática jurídica internacional, a qual é predominantemente, ocidental.

Observa-se que na atualidade ainda persistem práticas culturais que carecem de novas reflexões e ressignificações por parte da Teoria geral dos direitos humanos, fato este que nos levam a pensar sobre nós mesmos, nossas próprias identidades e a posição que outros discursos jurídicos não ocidentais ocupam frente ao diferente que turva, invade e se instaura tanto na sociedade, quanto nas comunidades internacionais.

Desta forma, salienta-se que abordar a prática da mutilação genital feminina desatrelada do predomínio da moralidade jurídico-normativa ocidental é uma das contribuições deste artigo, uma vez que se entende que o ocidentalismo normativo ocidental permanece recheado de características ideológicas que permeiam enfaticamente as relações socioculturais cotidianas, e estão diretamente implicadas sobre a invisibilização, o repúdio e a marginalização de questões culturais que fogem a esta dimensão de um uníssono discurso humanitário internacional, eminentemente universal. Importante salientar que o artigo em tela não vem em defesa da prática da mutilação genital feminine, todavia, percebe esta como uma questão problema que não pode, tampouco deve ser analisada apenas sob o foco e lentes da 
doutrina dos direitos humanos universal, de cunho eurocêntrica, que despreza eventuais peculiaridades e especificidades regionais e culturais.

Assim, acredita-se que a presente abordagem teórica - sociológica, antropológica, jurídica - abrirá um campo de discussões, tanto teóricas quanto práticas de fundamental importância para a Ciência Jurídica. Fato que não significa dizer que a interpretação da mutilação genital feminina, sob o foco das abordagens relativista ou multicultural dos direitos humanos, evidencia uma verdade jurídica melhor do que a perspectiva universal; pelo contrário, apenas se buscará demonstrar que a diversidade de postulados teóricos propiciam ganhos para desenvolvimento tanto do Direito Internacional, quanto dos Direitos Humanos, justamente, porque estas reflexões que virão, contribuirão com o espraiamento e com a visibilidade a outras formas de se interpretar o Direito, reconhecendo que este é resultado de diversos modos de existências e interações humanas, e não apenas como uma prática cultural que afronta os direitos humanos.

Finalmente, salienta-se o principal objetivo, o qual se logra atingir, integra o confrontamento da mutilação genital feminina à luz dos direitos humanos, em vista das implicações para a saúde mental e física que prática em discussão acarreta, por consistir em ofensa ao princípio basilar da dignidade da pessoa humana.

Esta pesquisa fez uso do método bibliográfico como instrumento de análise. Quanto à abordagem, esta se caracterizou por fazer uso de procedimentos metodológicos predominantemente qualitativos, oriundos da intepretação de ideias, categorias, signos e discursos, buscando entender os problemas apresentados pelos assuntos abordados e procurando adequar soluções para essas problemáticas. (CRESWELL, 2010).

Já o procedimento metodológico dedutivo permitiu que se fosse posto em dúvida a categoria universal, predominantemente ocidental, acerca dos Direitos Humanos, pelo fato de que a perspectiva universal parte da premissa de que estes direitos por serem universais, são aplicáveis a todos os seres humanos, sem qualquer tipo de distinção, mesmo que a nação a qual pertença possua seu competente escopo jurídico.

Finalmente, como método de procedimento, optou-se pelo descritivo comparativo, que segundo Vergara (2000, p. 69), “expõe características de determinada população ou de determinado fenômeno", podendo ou não conceber correlação entre as diversas variáveis, a fim de definir sua natureza. Enfim, a adoção a esses procedimentos se deu com o intuito de compreender o fenômeno da mutilação da genital feminina e sua relação com os diversos ordenamentos jurídicos. 


\section{Conceituando a Prática e Analisando as Consequências da Mutilação Genital Feminina}

A mutilação da genital feminina (MGF) constitui a ação de extirpar - total ou parcialmente - os órgãos genitais externos da mulher, ou seja, dar-se-á por toda e qualquer intervenção cirúrgica que incida sobre a remoção parcial ou total dos órgãos genitais femininos externos ou que provoquem leões nos órgãos genitais femininos por razões não médicas (OMS, 1997) como aponta Manuela Cunha, ao descrever que:

As consequências nocivas possíveis de intervenções genitais subsumidas na expressão mutilação genital feminina (MGF) na saúde sexual e reprodutiva das mulheres são conhecidas e têm gerado forte mobilização [...]. (CUNHA, 2013, p. 835).

Por conseguinte, estudos realizados pela Organização Mundial da Saúde (1997) constataram quatro formas que incidem na prática da MGF: a primeira é a clitoridectomia (realizada pela remoção parcial ou total do clitóris e/ou do prepúcio); a segunda forma se dá pela excisão, que consiste, além da clitoridectomia, na complementação pela amputação dos pequenos lábios, podendo ainda ocorrer a excisão dos grandes lábios; a terceira modalidade é chamada por infibulação ou circuncisão faraônica (ocorre quando há o estreitamento do orifício vaginal, que é feito através de cortes e oposição dos pequenos lábios ou dos grandes lábios, podendo ocorrer juntamente com a clitoridectomia e infibulação); e, por último, a intervenção por razões não medicas por questão de saúde. Ressalta-se que não é objetivo, neste trabalho, explorar as consequências que a prática da corte da genital feminina pode levar para a saúde das meninas e mulheres que passam por esse procedimento.

Todavia, é imprescindível evidenciar quão prejudicial pode ser esta prática para a saúde da mulher. A mutilação da genital afeta gravemente a vida das meninas e mulheres que passam por procedimento, não apenas do ponto de vista da saúde física, com envolvimento da saúde reprodutiva, mas também da saúde psicológica. (CAREJO; TEIXEIRA; LISBOA, 2017). Partindo de tais premissas, enfatizou-se a gravidade da problemática posta à saúde das mulheres que são submetidas ao corte da genital:

Mas não é apenas o corte propriamente dito que contribui para a extensa lista de consequências que afectam a saúde e a vida das mulheres e meninas que a ele são submetidas. $\mathrm{O}$ uso de facas, lâminas ou mesmo pedaços de vidro não esterilizados na realização do corte, a ausência de anestesia e/ou cuidados anti-sépticos [...] (CAREJO; TEIXEIRA; LISBOA, 2017, p. 89) 
É evidente a exposição a inúmeros riscos não só pela mutilação em si, mas pela forma e instrumentos utilizados para realização do procedimento, assim como também pelo ambiente no qual é realizado. Além disso, acentua-se que o processo que leva à mutilação pode demorar aproximadamente vinte minutos, deixando uma janela aberta no corpo da mulher para incontáveis vírus e bactérias que estejam no local. Outro fator que agrava a realização da prática do corte genital é a reutilização das lâminas ou projéteis já utilizados em outras mulheres, e não esterilizados, podendo assim aumentar, significativamente, as chances de se contrair alguma doença sexualmente transmissível.

Mas não só a reutilização de objetos em várias mulheres pode expô-las aos ricos de doenças transmitidas sexualmente, a própria ferida causada pelo corte pode ser o fator causador desse risco, dentre inúmeros outros. Como bem sustenta Yasmina Gonçalves, ao afirmar que: "hemorragias, infecções localizadas e septicemias [...] infecções genitais e urinárias, dores e lacerações durante as relações sexuais, hemorragias e fístulas obstétricas acarretando dores, incapacidade, infertilidade". (GONÇALVES, 2015, p. 3).

Unido a esse fator de perigo, há também o prejuízo à vida sexual da mulher, vez que a mutilação, como pode-se imaginar, causa graves lesões ao tecido do órgão genital feminino, pois a MGF é realizada, na maioria das vezes, com métodos rústicos e brutais. "A penetração vaginal feita através do tecido genital lesado e cicatrizado pode ser difícil ou impossível, existindo ruptura do tecido, provocando novas hemorragias e dor intensa" (GONÇALVES, 2005, p. 21). Por conta das lesões deixadas pela MGF, para que as mulheres tenham seu primeiro ato sexual, é necessário que se aguarde uma previa dilatação gradual e dolorosa da abertura que restou após a mutilação. Em alguns casos, há necessidade de que se faça uma incisão prévia ao ato sexual.

\section{Tematizando a Multiculturalidade sob a Égide dos Direitos Humanos}

Em prima face, faz necessária uma breve explanação do que se entende por direitos humanos. Figura, como definição simplória, o entendimento de que se destinam esses direitos à proteção de toda pessoa humana, independentemente, de qualquer condição particular, entendendo a pessoa humana como um fim em si mesma (abordagem universalista dos Direitos Humanos). Nas palavras de Valério Mazzuoli, "basta a condição de ser pessoa humana para que todos possam vindicar seus direitos violados, tanto no plano interno como no contexto internacional" (2016, p. 895). 
É possível afirmar, com base nesse pressuposto, que a simples condição de ser humano já reveste como ser passível de proteção pelos Direito Humanos. Corroborando tal afirmação, há que se citar a definição elencada por Paulo Henrique Gonçalves Portela, que conceitua os direitos humanos "como aqueles direitos essenciais para que o ser humano seja tratado com dignidade que lhe é inerente e aos quais fazem jus todos os membros da espécie humana, sem distinção de qualquer espécie”. (PORTELA, 2016, p. 819).

A premissa pela qual os direitos humanos são direitos característicos de qualquer indivíduo, autonomamente a qualquer valor ou predeterminação estatal ou social, faz-se revelar um fundamento pretérito desses garantias a toda e qualquer forma de Estado ou organização político-social, a tal passo que a proteção independe de qualquer sistema estatal, não se esgotando nesses, podendo ir além da soberania do Estado (MAZZUOLI, 2016). Partindo de tais definições, temos que os direitos humanos fazem uma frente de defesa contra excessos de poder, sendo esse advindo do Estado por meio dos seus entes, como também do abuso de poder imposto por outros seres humanos, pessoas naturais detentoras dos mesmos direitos, mas que em posições sociais impõe-se condutas (PORTELA, 2016).

Preciosas palavras de Valério Mazzuoli (2014), em seu Curso de Direitos Humanos:

\begin{abstract}
No que tange à proteção dos direitos das pessoas, tem-se que os "direitos humanos" (internacionais) são mais amplos que os "direitos fundamentais" (internos). Esses últimos, sendo positivados nos ordenamentos jurídicos internos, não tem um campo de aplicação tão extenso quanto o dos direitos humanos, ainda mais quando se leva em conta que nem todos os direitos fundamentais previstos nos textos constitucionais contemporâneos são exercitáveis por todas as pessoas indistintamente. (MAZZUOLI, 2014, p. 24) (Grifo do autor)
\end{abstract}

Com tal afirmação, distinguimos, de forma breve, Direitos Humanos e Direitos Fundamentais, sendo solidificado que direitos humanos estão relacionados a uma ordem internacional, ao passo que os direitos fundamentais pertencem a um determinado ordenamento jurídico interno estatal, podendo considerar este último uma união material da proteção internacional com a internalização por parte do estado soberano. Contudo, o mesmo autor assevera como sábias palavras que os Direitos Humanos "podem ser vindicados indistintamente por todos os cidadãos do planeta em quaisquer condições” (MAZZUOLI, 2016, p. 898).

Tal pensamento reafirma a ideia de proteção ilimitada intrínseca à pessoa humana, altivamente a condições imperativas. As garantias atinentes aos direitos humanos estão fundamentadas em um caráter de segurança, em uma necessidade de garantir, a igualdade dos sujeitos de direitos, fazendo-se respeitar a dignidade da pessoa e os conceitos que dela advém, 
dentre os quais valores de vida, liberdade, igualdade e solidariedade. (SILVEIRA e ROCASOLANO, 2010).

A dignidade da pessoa humana é alicerce central das garantais que os direitos humanos visam a segurar, sendo supedâneo de tais proteção. Preciosa a afirmação também trazida por Paulo Henrique Gonçalves Portela quanto à fundamentação dos Direitos Humanos:

[...] os direitos humanos se fundam no reconhecimento da dignidade inerente a todos os membros da espécie humana, entendidos como iguais em sua essência, não obstante qualquer peculiaridade física, mental ou intelectual ou qualquer outro aspecto de sua existência. (PORTELA, 2016, p. 820)

Em outras palavras, os Direitos Humanos pertencem ao indivíduo humano pela sua simples natureza humana, tendo como razão essa própria natureza pura e simplesmente, independentemente de qualquer aspecto ou valor individual, sendo essa razão definida em sua própria existência.

\section{Globalização, a Multiculturalidade e os Direitos Humanos}

Um dos grandes desafios impostos aos Direitos Humanos, nos dias atuais, é sustentar uma universalidade, esta que esbarra de frente às mais diversas culturas. Adelia Cortina conceitua multiculturalismo, de maneira geral, como sendo "um conjunto variado de fenômenos sociais, que derivam da difícil convivência e/ou coexistência em um mesmo espaço social de pessoas que se identificam com culturas diferentes" (CORTINA, 2005, p.163).

Com tal pensamento, podemos esboçar a ideia de que o multiculturalismo é a existência, em um mesmo espaço, de diversos valores que se identificam entre si mesmo, não se anulando. Neste mesmo sentido, expõem Boaventura e João Arriscado Nunes (2003) que:

\footnotetext{
A expressão multiculturalismo designa, originariamente, a coexistência de formas culturais ou de grupos caracterizados por culturas diferentes no seio das sociedades modernas [...]. Existem diferentes noções de multiculturalismo, nem todas no sentido 'emancipatório'. O termo apresenta as mesmas dificuldades e potencialidades do conceito de 'cultura', um conceito central das humanidades e das ciências sociais e que, nas últimas décadas, se tornou terreno explícito de lutas políticas. (SANTOS; NUNES, 2003, p.26).
}

Verifica-se que multiculturalismo consiste na coexistência pacífica e não hegemônica de valores sociais, políticos, econômicos e culturais, sem que haja qualquer tipo de imposição preceitos tidos como universais. Assim, é basicamente a conivência de forma horizontalizada 
das culturas existentes. Como destaca primorosamente Dulce de Queiroz Piacentini: “a intensificação da globalização econômica ocorrida na segunda metade do século XX contribuiu para que a diversidade cultural despontasse como um dilema a ser discutido nas arenas política, jurídica, social e econômica”. (PIACENTINI, 2007, p. 64).

É de grande relevância o contexto que a intensa globalização impôs ao cenário dos Direitos Humanos, tal cenário não suprimiu as culturas, como há de se imaginar, em tese, pelo imperialismo ocidental, já discutido anteriormente, a globalização expôs as diferenças de valores culturais existentes nas sociedades em um quadro mundial. Dentro dessa premissa, os processos de globalização acabam por gerar processos de localização, sendo que estes ascendem os holofotes, exteriorizando as existências de distintas manifestações culturais que postulam um espaço ao ar livre para respirar, sentir-se respeitadas. (SANTOS, 2001; PIACENTINI, 2007).

Interessante e preciso é o pensamento do professor Boaventura de Sousa Santos (2001) sobre a relação dos Direitos Humanos com o contexto de globalização. Para o autor, a complexidade destes direitos dar-se pelo fato de poderem ser concebidos tanto pela forma de localismo globalizado, quanto por uma forma de cosmopolitismo. Em suas próprias palavras, este afirma que se propõe a "identificar as condições culturais através das quais os Direitos Humanos podem ser concebidos como cosmopolitismo ou globalização contra hegemônica" (SANTOS, 2001, p. 15).

Por conseguinte, é neste contexto não hegemônico, distante de qualquer posição imperativa, que se deseja interpretar a multiculturalidade com finalidade a análise da mutilação feminina. Para compreendermos essa categoria conceitual socioantropológica, faz-se necessário entendermos melhor o pensamento de Boaventura de Sousa Santos, no sentido que de:

[...] os direitos humanos têm de ser reconceitualizados como multiculturais. O multiculturalismo, tal como entendo, é precondição de uma relação equilibrada e mutuamente potenciadora entre a competência global e a legitimidade local, que constituem os dois atributos de uma política contra hegemônica de direitos humanos [...] (SANTOS, 2001, p. 16)

É necessário que se reconheça efetivamente a diversificação e diferenças culturais, como forma de propiciar o respeito aos Direitos Humanos. Em comentário sobre a citação supramencionada (SANTOS apud PIOVESAN, 2008), apresenta que: 
[...] Prossegue o autor defendendo a necessidade de superar o debate sobre universalismo e relativismo cultural, a partir da transformação cosmopolita dos direitos humanos. Na medida em que todas as culturas possuem concepções distintas de dignidade humana, mas são incompletas; haver-se-ia que aumentar a consciência dessas incompletudes culturais mútuas, como pressuposto para um diálogo intercultural. A construção de uma concepção multicultural dos direitos humanos decorreria desse diálogo intercultural. (SANTOS apud PIOVESAN, p.153-154,)

O pensamento sobre Direitos Humanos há que ser desenhado de forma a alinhar-se aos contornos de um conjunto de nações multiculturais, nos quais, em devidas localidades, convivem com diversos valores únicos. Devendo, os Direitos Humanos, ter uma posição de conjuntamente entre todos os povos potencializar a individualização e valorização uniforme de todos os valores. Entretanto, não podemos confundir essa potencialização com a errônea valorização de práticas que estejam em desacordo com os valores naturais do homem, defendidos pelos Direitos Humanos, em seu linear mínimo.

Assim como o discurso relativista, o discurso multiculturalista não pode servir de sustentáculo de ações que prejudique a integridade do ser humano, ou coisificando, tornando-o objeto de segregação em seu meio local. Pois o indivíduo possui uma dignidade absoluta e irredutível, que deve ser defendida contra atos do Estado ou mesmo valores da sua própria sociedade que subjugam a dignidade humana. (SANTOS, 2001).

\section{A Mutilação Genital Feminina frente aos Direitos Humanos e na Contramão da Dignidade da Pessoa Humana?}

Direitos Humanos são aqueles direitos essenciais ao ser humano, e para ter estes direitos garantidos, basta ter a condição de ser humano, uma vez que esses direitos inerentes à espécie humana. Por conseguinte, salienta-se que, como valores básicos de cada indivíduo humano, os direitos humanos, claramente vão de encontro a todo e qualquer ato ou processo social e/ ou cultural que implique na amputação de órgãos ou tecidos perfeitamente saudáveis. Logo, a mutilação da genitália feminina qualifica-se como uma afronta aos direitos das mulheres. E como de fato a mutilação ocorre no período infante, torna-se também ofensa ao direito das crianças. Dulce de Queiroz Piacentini é clara ao afirmar que: "Tendo-se em conta que a mutilação ocorre quando elas têm geralmente entre quatro e oito anos, tal prática viola também o direito das crianças." (PIACENTINI, 2007, p. 123).

Um ponto a ser levando em consideração é a questão dos valores culturais e os Direitos Humanos, como visto a cima, no debate sobre universalismo e relativismo, a questão sobre 
imposição de valores e relativização de práticas é algo de extremos. Contudo, sobre a ótica dos Direitos Humanos, a integridade física e psicológica, bem como a não descriminação e acesso ao melhor padrão de saúde sustentável são questões que transcendem valores, pois são universais. (PIACENTINI, 2007).

Neste contexto, a discussão em torno desse tema levou em 06 de fevereiro de 2014, o então Secretário Geral da Organização das Nações Unidas (ONU), Ban Ki-Moon, se pronunciar em mensagem aberta sobre o tema:

\begin{abstract}
Devemos lutar para preservar o melhor de cada cultura e deixar para trás o que não é bom. Não há nenhuma razão religiosa, de saúde ou de desenvolvimento para mutilar ou cortar qualquer menina ou mulher. Embora alguns argumentem que é uma "tradição", devemos lembrar que a escravidão, as mortes por honra e outras práticas desumanas foram defendidas com o mesmo argumento. Apenas porque uma prática dolorosa existe há muito tempo não justifica sua continuação. Todas as "tradições" que rebaixam, humilham e ferem são violações dos direitos humanos que devem ser ativamente combatidas até que acabem. [...]. (ONU, 2014).
\end{abstract}

Importante destacar que estes direitos estão especificados e possuem a adesão de diversos tratados regionais e internacionais, sendo também abrigados por um Sistema Global de Proteção. Como também, através de conferências e convenções mundiais, como, por exemplo, os desenvolvidos pelas Nações Unidas. Tratados internacionais, como exemplo a Convenção sobre a Eliminação da Discriminação contra as Mulheres e Convenção sobre os Direitos da Criança, e tratados regionais, como a Carta Africana sobre Direitos Humanos e dos Povos e Protocolo sobre o Direitos da Mulher na África, e outros documentos de consenso, tais como Declaração de Beijing e Declaração Universal da UNESCO sobre Diversidade Cultural, fortalecem os direitos e a luta mulheres e meninas que se põem na contramão desta prática cultural.

Ademais, observa-se que muitos dos países onde ocorre a prática da mutilação da genitália feminina são membros da ONU. Assim, convém citar que a Declaração Universal dos Direitos do Humanos, de 1948, já preconizava a igualdade, direito à segurança e à proteção, a não submissão a tratamentos cruéis e degradantes, "Todo o indivíduo tem direito à vida, à liberdade e à segurança pessoal". (ONU,1948).

Prescreve in verbis o artigo $5^{\circ}$ da referida declaração: "Ninguém será submetido à tortura, nem a tratamento ou castigo cruel, desumano ou degradante" (ONU, 1948). A referida norma põe a salvo todos os indivíduos contra qualquer tratamento indigno a sua condição precípua da pessoa humana, torna por óbvio resguardadas assim as mulheres contra práticas como a do corte genital. 
Nesse contexto, corrobora tal premissa, a luta travada contra a discriminação e contra a inferioridade entre homens e mulheres se faz o principal objetivo da Convenção para a Eliminação de Todas as Formas de Discriminação Contra as Mulheres, de 1979, a saber:

Os Estados Partes tomarão todas as medidas apropriadas para: a) Modificar os esquemas e padrões de comportamento sociocultural de homens e mulheres, com vistas a alcançar a eliminação dos preconceitos e práticas consuetudinárias, ou de qualquer outro tipo, que estejam baseados na ideia de inferioridade ou superioridade de qualquer dos sexos ou em papéis estereotipados de homens e mulheres. (ONU,1979, s/p.).

Neste sentido, é imperioso citar a Convenção Sobre os Direitos das Crianças como fundamento de proteção aos direitos desses seres que estão pleno desenvolvimento físico e psíquico, podendo ser fonte de inspiração para o combate ao MGF, posto que as nações se comprometeram a adotar "todas as medidas eficazes e adequadas com vista a abolir as práticas tradicionais prejudiciais à saúde das crianças". (UNICEF; 1989, s/p.).

A dignidade da pessoa humana apresenta-se como um "superprincípio" que irradia luz a todos os outros princípios e normas. Por conseguinte, não se concebe pensar em interpretação, aplicação ou elaboração de normas jurídicas sem o crivo da dignidade da pessoa humana (NUNES, 2010, p. 65).

[...] a dignidade da pessoa encontra-se, de algum modo, ligada (também) à condição humana de cada indivíduo, não há como desconsiderar a necessária dimensão comunitária (ou social) desta mesma dignidade de cada pessoa e de todas as pessoas, justamente por serem todos reconhecidos como iguais em dignidade e direitos (na iluminada fórmula da Declaração Universal de 1948) e pela circunstância de nesta condição conviverem em determinada comunidade. Aliás, consoante já anunciado, a própria dimensão ontológica (embora não necessariamente biológica) da dignidade [...] marca todas relações humanas e, portanto, também o reconhecimento dos valores (assim como princípios e direitos fundamentais) [...]. (SARLET, 2007, p. 369-370).

Desta forma, o fundamento basilar dos Direitos Humanos é a própria dignidade humana, tendo como escopo os direitos de primeira dimensão: liberdade, igualdade e solidariedade, sendo assim, a MGF afrontar, especificamente, os dois primeiros direitos. A prática da circuncisão feminina vai de encontro à liberdade individual da pessoa humana, uma vez que as meninas que sofrem com esta prática, sequer têm o direito de escolher, ou mesmo sabem por menores, o que realmente ocorrerá, sendo que, dessa forma, a atinge a autonomia, a independência.

No que concerne à igualdade, esta está diretamente ligada à desigualdade de gênero, uma vez mantém a mulher numa posição inferior à figura do homem. Ao mutilar uma parte do 
corpo feminino, além do sofrimento emocional, atinge seu desenvolvimento, sua fertilidade, imediatamente atinge a sua dignidade humana. Afirma Otto-Oyortey (2007, p.13) afirma que "quanto mais extensiva for a MGF/CGF, maiores serão os riscos de saúde, incluindo cesarianas, hemorragias pós-parto e uma estadia mais longa no hospital.” O que coloca em risco não apenas a vida da própria mulher, vítima de tal crueldade, mas também a vida de seus filhos durante o parto. Por serem vulneráveis, crianças e mulheres estão sujeitas a práticas nefastas, como a MGF. Assim, apontam Vladmir Oliveira da Silveira e Maria Mendez Rocasolano (2010):

Todo ato de tortura ou trato cruel, ou pena degradante ou desumano, constitui uma ofensa à dignidade humana e será condenado como violação dos propósitos de carta das Nações Unidas e dos Direitos Humanos e liberdades fundamentais proclamados na Declaração Universal dos Direitos Humanos. (SILVEIRA; ROCASOLANO apud ROCCO, 2010, p. 225).

A este respeito, assevera, Yasmina Gonçalves (2007, p.26) que “A MGF é uma violação dos Direitos Humanos, Direitos da Mulher e Direitos da Criança.” E complementa expondo que, para se mudar comportamentos culturais que são intrínsecos numa sociedade, é necessário agir em áreas como a educação, saúde, e realizar ações intervenções sociais, pois, somente dessa forma, poderia ocorrer mudanças capazes de mudar a realidade de inúmeras mulheres que sofrem com esta prática e não buscando combater a discriminação ou imputando penas para tais condutas.

O silêncio ensurdecedor de inúmeras mulheres e meninas clama por uma efetividade no combate à referida prática, na busca da edificação da sua dignidade enquanto ser, ser este que precisa muito mais do que proteção jurídica, mas sim acolhimento humano e de ações que as ajudem a superar e combater esse mal que assolam muitos países.

\section{Considerações Finais}

O multiculturalismo, entendido na existência concomitante de diversas culturas, ou grupos sociais, é valorizado por raízes distintas em meio a sociedades modernas. Estando, portanto, esse fenômeno intimamente ligado à globalização das sociedades e suas constantes conversação intercultural. Assim, sendo guiados pelas garantias e preceitos que sustentam a condição humana, foi primordial, assimilar como o corte genital feminino vai de encontro a direitos inquestionáveis da nossa condição humana, pois, como ser humano, todos nós somos plenamente possuidores de direitos e garantias, assegurados frente a imposições de qualquer sociedade ou Estado. 
A perspectiva teórica relativista, em contrapartida à universalista, critica a característica de universalidade, principalmente, ao ressaltar que o termo universal é tendenciosamente impositivo. Essa teoria observa sim garantias mínimas indistintas a cada ser humano, todavia, são levados em consideração os aspectos valorativos individuais de cada sociedade, cada comunidade.

Observa-se que, mesmo em suas distinções, ambas têm como plano de fundo garantias básicas, inerentes à individualidade ou coletividade humana, dentre essas garantias é possível citar, de modo demonstrativo, a liberdade individual, o acesso à saúde integral, não submissão à tortura ou práticas degradantes, desumanas ou cruéis.

Por conseguinte, o debate atual em contexto de diversidade e interculturalidade sugere que não se deve, sob hipótese alguma, realizar confrontação entre culturas, no sentido de verticalizar seus preceitos e valores, aplicando critérios de superioridade e/ou inferioridade, de determinada cultura em relação a outra, ou estabelecer qualquer espécie de imperialismo cultural, tende-se à prevalência de determinadas culturas em relação a outras, visto que, em uma perspectiva global, todas se conglomeram, não havendo "pureza cultural", tornando-se, nos tempos modernos multiculturais, por terem condensado seus valores, sem padrões, perfazendo novos.

Além do exposto, há que se afirmar que a simples pretensão de imposição cultural se perfaz, em si, uma agressão contra os valores que o corolário da dignidade humana visa proteger. A remoção, parcial ou total, dos órgãos genitais femininos externos por razões não médicas, é um prática perpetuada e sustentada por valores sociais e culturais. As sociedades que realizam a mutilação da genital feminina atribuem tal feito à malignidade do órgão genital feminino.

Não obstante ao exposto, a defesa da mutilação da genitália feminina alega valores culturais, porém, tal prática viola direitos e garantias em um plano superior aos valores culturais, afronta, de forma brutal, a dignidade humana e os valores essenciais para a vida humana. O corte genital feminino é uma prática discriminatória, que tenta usar de fundamentos incoerentes para justificar o abuso da dignidade das mulheres. Não se trata de valores culturais, não é possível sequer datar ou documentar as origens dessa monstruosidade nos seios das sociedades que praticam tal atrocidade.

Dentro das sociedades que praticam a mutilação genital, não há que se falar em participação na prática da comunidade de forma voluntária, sendo imposto o corte como forma de assimilação social, e a não realização como forma de segregação. Se recusar a ser mutilada, 
pode acarretar em risco à sobrevivência do jovem no contexto sociocultural das localidades. A MFG é vista como elemento essencial para o desenvolvimento da mulher perante a sociedade.

Finalmente, conclui-se que esta prática constitui uma notória violação aos direitos e garantias fundamentais da humanidade, em que os motivos sustentados para a continuidade dessa prática, demonstra um maciço e enviesado conteúdo de domínio masculino, cujo o objetivo é deter a coisificação da mulher submissa, objeto de exposição masculino. Essa prática deve ser erradicada das sociedades onde persistem em existir, visto ser uma ofensa à vida humana, uma afronta direta contra a liberdade feminina, um atentado contra os direitos das mulheres, e explícita violação à dignidade da pessoa humana.

Faz se imperioso pontuar que este estudo não possuía por finalidade apresentar soluções acerca da mutilação genital feminina - MGF, mas sim suscitar uma reflexão jurídica, do ponto de vista humano e cultural, pautado por direitos e garantias que estruturam e dão azo à dignidade da pessoa humana.

\section{Referências}

BRASIL, Decreto $\mathrm{n}^{\circ}$ 4.377, de 13 de setembro de 2002. Promulga a Convenção sobre a Eliminação de Todas as Formas de Discriminação contra a Mulher, de 1979, e revoga o Decreto no 89.460, de 20 de março de 1984. Disponível em:< http://www.planalto.gov.br/ccivil_03/decreto/2002/d4377.htm> Acesso em: 03 mar. 2018.

,. Diário da República, 1. a série - N. ${ }^{\circ} 253$ - 31 de dezembro de 2013. III Programa de acção para a prevenção e eliminação da mutilação genital feminina, 2014-2017. Disponível em: $<$ https://www.cig.gov.pt/wp-content/uploads/2014/07/III-Programa-de-A\%C3\%A7\%C3\%A3o-para-apreven\%C3\%A7\%C3\%A3o-e-elimina\%C3\%A7-\%C3\%A3o-da-MGF-Anexo-DR.pdf> acessado em: 10 de maio de 2018.

CEREJO, Dalila; TEXEIRA, Ana Lúcia; LISBOA, Manuela. Mutilação genital feminina. Contextos socioculturais, discursos e percepções sobre a mutilação genital feminina. 2017 p. 83-103.

CORTINA, Adela. Cidadãos do Mundo - Uma teoria da cidadania. São Paulo: Loyola, 2005.

CRESWELL, J. W. W. Projeto de pesquisa: métodos qualitativo, quantitativo e misto. 2. ed. Porto Alegre: Bookman, 2010.

CUNHA, Manuela Ivone. Género, cultura e justiça: A propósito dos cortes genitais. Análise Social. Edição 4. Lisboa, Portugal: 2013. Disponível na Internet: < http://www.ics.ul.pt> Acesso em: 07 mai. 2018 
GONÇALVES, Yasmina. Mutilação genital feminina. Associação para o Planeamento da Família. Lisboa. 2015.

Mutilação Genital Feminina - um retrato possível. p. 25-67. In: FRADE, Alice

(Org.). Por Nascer Mulher... um outro lado dos Direitos Humanos. Associação para o Planeamento da Família. Lisboa, 2007.

. Mutilação genital feminina. Associação para o Planeamento da Família. Lisboa. 2005

MAZZUOLI, Valério Oliveira. Curso de Direito Internacional Privado. 10 ed. São Paulo: Revista dos Tribunais, 2016.

,. Curso de Direitos Humanos. São Paulo: Método, 2014.

NUNES, Rizzatto. O princípio constitucional da dignidade da pessoa humana: doutrina e jurisprudência. ed. 3, São Paulo: Saraiva, 2010. Disponível em: <https://integrada.minhabiblioteca.com.br/\#/books/9788502135413/cfi/4!/4/4@0.00:0.00.

>Acesso em: 06 mai. 2018.

OMS; ADPF. Ace ONU (1997) Convenção Sobre a Eliminação de Todas as Formas de Discriminação Contra as Mulheres. Eliminação da mutilação Genital Feminina: Declaração conjunta OHCHR. ONUSIDA, PNUD, UNECA, Unesco, UNFPA, ACNUR, UNICEF, UNIFEM, (2008). Lisboa.

Disponível em: < $\quad$ http://www.institutocamoes.pt/images/cooperacao/eliminacao_mgf_declarconjt.pdf> Acesso em: 07 mai. 2018

ONU. Eliminação da Mutilação genital feminina, 2014. Declaração conjunta OHCHR, ONUSIDA, PNUD, UNECA UNESCO, UNFPA, ACNUR, UNICEF, UNIFEM, OMS. Disponível em: <http://www.institutocamoes.pt/images/cooperacao/eliminacao_mgf_declarconjt.pdf >. Acesso em: 2 set. 2017.

,.. Assembleia Geral das Nações Unidas. Declaração Universal dos Direitos Humanos. 1948. Disponível em <https://www.unicef.org/brazil/pt/resources_10133.htm>. Acesso em 11 mai. 2018.

OTTO-OYORTEY, Naana. Mutilação Genital Feminina. Uma preocupação da Saúde e Direitos Sexuais e Reprodutivos. p. 10-15. In: FRADE, Alice (Org.). Por Nascer Mulher... um outro lado dos Direitos Humanos. Associação para o Planeamento da Família. Lisboa, 2007.

PORTELA, Paulo Henrique Gonçalves. Direito Internacional Público e Privado. $8^{a}$ edição, revistado e atualizado. São Paulo: Editora Saraiva, 2016.

PIOVESAN, Flávia. Direitos Humanos e o direito constitucional internacional. 9. ed. São Paulo: Saraiva, 2008.

Direitos humanos: desafios da ordem internacional contemporânea. In: PIOVESAN, Flávia (Coord.). Direitos humanos. Curitiba: Juruá Editora, 2006. Vol. 1. pp. 1537. 
PIACENTINI, Dulce de Queiroz. Direitos Humanos e Interculturalismo: Análise da Prática Cultural da Mutilação Genital Feminina. Dissertação (Mestrado em Direito) - Centro de Ciências Jurídicas, Universidade Federal de Santa Catarina, Florianópolis, 2007.

SANTOS, Boaventura de Sousa. NUNES, João Arriscado. Introdução: para ampliar o cânone do reconhecimento, da diferença e da igualdade. In: SANTOS, Boaventura de Sousa (org.). Reconhecer para libertar: os caminhos do cosmopolitismo multicultural. Rio de Janeiro: Civilização Brasileira, 2003 (Série reinventar a emancipação social: para novos manifestos, v.3).

„. Para uma concepção multicultural dos Direitos Humanos. 2001. Disponível

em:

<http://www.boaventuradesousasantos.pt/media/pdfs/Concepcao_multicultural_direitos_hum anos_ContextoInternacional01.PDF>_Acesso em: 04 mai. 2018.

SARLET, Ingo Wolfgang. As dimensões da dignidade da pessoa humana: construindo uma compreensão jurídico-constitucional necessária e possível. Revista Brasileira de Direito Constitucional, $\quad$ n. $\quad 9, \quad$ jan-jul, 2007. Disponível em: <http://www.escolasuperiordedireito.com.br/RBDC/RBDC-09/RBDC-09-361-

Ingo_Wolfgang_Sarlet.pdf.> Acesso em: 06 mai. 2018.

SILVEIRA. Vladmir Oliveira da. Direitos Humano: conceito, significados e funções / Valdir de Oliveira Silveira; Maria Mendez Rocasolano. São Paulo. Saraiva. 2010.

SILVEIRA. Vladmir Oliveira da; ROCASOLANO, Maria Mendez. Direitos Humanos: conceito, significados e funções. São Paulo: Saraiva. 2010.

UNICEF, Convenção sobre os Direitos da Criança, Adotada em Assembleia Geral das Nações Unidas em 20 de novembro de 1989. Disponível em: <https://www.unicef.org/brazil/pt/resources_10127.htm> Acesso em: 05 mai 2018

VERGARA, Sylvia Constant.Projetos e relatórios de pesquisa em administração. 3. ed. São Paulo: Atlas, 2000.

Como citar este artigo (Formato ABNT):

ALENCAR FILHO, José Humberto de; IFADIREÓ, Miguel Melo; ALBUQUERQUE FILHO, José Antônio de. O Direito Internacional Humanitário Frente à Problemática da Mutilação Genital Feminina. Id on Line Rev.Mult. Psic., 2019, vol.13, n.43, p. 14-29. ISSN: 1981-1179.

Recebido: $15 / 11 / 2018$

Aceito: 19/11/2018 